\title{
Inhibition of Stat3 activation and tumor growth suppression of non-small cell lung cancer by G-quartet oligonucleotides
}

\author{
PRIYA WEERASINGHE ${ }^{1}$, GABRIELA E. GARCIA ${ }^{1}$, QIQING ZHU ${ }^{1}$, \\ PING YUAN ${ }^{3}$, LILI FENG ${ }^{1}$, LI MAO ${ }^{3}$ and NAIJIE JING ${ }^{1,2}$ \\ ${ }^{1}$ Department of Medicine, and ${ }^{2}$ Dan Duncan Cancer Center, Baylor College of Medicine; ${ }^{3}$ Department of Thoracic/ \\ Head and Neck Medical Oncology, The University of Texas MD Anderson Cancer Center, Houston, TX, USA
}

Received February 20, 2007; Accepted April 12, 2007

\begin{abstract}
Lung cancer is the leading cause of cancer mortality in the United States. Despite advances made over the past decades, the overall survival of patients with lung cancer remains dismal. Here we report novel G-quartet oligodeoxynucleotides (GQ-ODN) that were designed to selectively target signal transducer and activator of transcription 3 (Stat3), in the treatment of human non-small cell lung cancer (NSCLC). The objective of this study was to evaluate the effects of two novel GQ-ODN STAT3 inhibitors, T40214 and T40231, on NSCLC bearing nude mice. NSCLC bearing nude mice were assigned to 5 groups, which were treated by vehicle, control ODN, T40214, T40231, and Paclitaxel, respectively. Tumors were measured, isolated and analyzed using Western blotting, immuno-histochemistry, RPA and TUNEL. Results show that GQ-ODN T40214 and T40231 significantly suppress the growth of NSCLC tumors in nude mice by selectively inhibiting the activation of Stat 3 and its downstream proteins Bcl-2, Bcl- $\mathrm{x}_{\mathrm{L}}$, Mcl-1, survivin, VEGF, Cyclin D1 and c-myc; thereby, promoting apoptosis and reducing angiogenesis and cell proliferation. These findings validate Stat 3 as an important molecular target for NSCLC therapy and demonstrate the efficacy of GQ-ODN in inhibiting Stat3 phosphorylation.
\end{abstract}

\section{Introduction}

Lung cancer is one of the most prevalent cancers and a leading cause of cancer mortality worldwide. In the United States, approximately 170,000 people are diagnosed with lung cancer each year $(1,2)$; approximately $85 \%$ of those diagnosed die of the disease. The number of lung cancer deaths exceeds those due to breast, prostate, and colon cancers combined (3). Lung cancer has two major subtypes

Correspondence to: Dr Naijie Jing, Department of Medicine, Baylor College of Medicine, Houston, TX 77030, USA

E-mail: njing@bcm.tmc.edu

Key words: G-quartet oligonucleotides, signal transducer and activator of transcription 3, non-small cell lung cancer, apoptosis, angiogenesis based on histology, i.e. small cell lung cancer (SCLC) and non-small cell lung cancer (NSCLC) which account for $85 \%$ of all lung cancers. More than $60 \%$ of all NSCLC patients have advanced or metastatic tumors at the time of diagnosis and are not suitable for surgery (3). Despite advances made in treating the disease over the past two decades, the overall survival of patients with NSCLC remains extremely poor (4). Therefore, innovative treatment approaches that employ new agents targeting novel molecules are urgently needed. In this regard, Stat3, a critical mediator of oncogenic signaling that is highly activated in a wide variety of human tumors (5), may hold promise.

Signal transducer and activator of transcription (STAT) proteins were discovered as latent cytoplasmic transcription factors (6). Seven known mammalian STAT proteins (i.e., Stat1, 2, 3, 4, 5a, 5b, and 6) are involved in immune response, inflammation, proliferation, differentiation, development, cell survival, and apoptosis (5). These proteins contain several domains: a tetramerization domain, a coil-coil domain, a DNA-binding domain, a linker domain, an Src-homology 2 (SH2) domain, a critical tyrosine residing near the C-terminal end, and a C-terminal transactivation domain $(7,8)$. STAT proteins are activated in response to the binding of a number of ligands, including cytokines (e.g., IL-6) and growth factors (e.g., EGF), to their cognate cell surface receptors, and are recruited to specific phosphotyrosine residues within receptor complexes through their SH2 domains; they subsequently become phosphorylated on the tyrosine residue within their $\mathrm{C}$-terminus and dimerize through reciprocal interactions between the SH2 domain of one monomer and the phosphorylated tyrosine of the other. The activated dimers translocate to the nucleus, where they bind to DNA-response elements in the promoters of target genes and activate specific gene expression programs (9).

Stat 3 has been identified as an important target for cancer therapy, since it participates in oncogenesis through the upregulation of genes encoding apoptosis inhibitors $\left(\mathrm{Bcl}-\mathrm{x}_{\mathrm{L}}\right.$, Mcl-1, and survivin), cell-cycle regulators (cyclin D1 and c-myc), and inducers of angiogenesis (VEGF) (9). Mounting evidence has shown that Stat3 is also constitutively activated in many human cancers, including $82 \%$ of prostate cancers, $70 \%$ of breast cancers, over $90 \%$ of head and neck cancers, and more than $50 \%$ of lung cancers (10-13). These findings provide a strong rationale for targeting Stat 3 to treat human cancers. 
Recently, we laid the groundwork to develop G-quartet oligodeoxynucleotide (GQ-ODN), which forms G-quartet helical DNA structures, as a potent inhibitor of Stat3 activation. In our preliminary studies, we have: i) demonstrated that GQ-ODN selectively inhibits Stat 3 activation in cancer cells; ii) developed a novel delivery system for GQ-ODN, to increase drug activity in cells and in vivo; and iii) shown that GQ-ODN T40214 and T40231 significantly suppress tumor growth and greatly increase the survival of nude mice with tumors in which Stat3 is activated (14-16). This report is a part of our systematic in vivo examination, which aims to determine whether Stat 3 as an oncogenic signaling molecule will have the same influence on tumor progression in different human cancers and whether GQ-ODN will have a similar effect on suppressing tumor growth in different xenografted models under the same conditions. Here we have demonstrated that: i) as a critical oncogenic signaling pathway, Stat 3 strongly influences the progression of NSCLC in vivo; and ii) targeting the Stat 3 molecule with GQ-ODN constitutes a novel and potent therapeutic treatment for NSCLC. We also provide experimental evidence for the proposed mechanism, that a tyrosine-phosphorylated STAT dimer is quickly dephosphorylated when the STAT dimer is dissociated from DNA in cells $(17,18)$. Based on the results, we suggest that GQODN is a novel and promising class of anti-cancer drug in the treatment of metastatic tumors.

\section{Materials and methods}

Materials. The following polyclonal antibodies were obtained from Santa Cruz Biotechnology, Inc. (Santa Cruz, CA): antiStat3; anti-Stat1; anti-Cyclin D1 against amino acids 1-295, which represents full-length cyclin D1 of human origin; anti-VEGF; anti-Bcl- $\mathrm{X}_{\mathrm{L}}$; and anti-Bcl-2. Phospho-specific antibodies, p-Stat1 and p-Stat3, were purchased from Cell Signaling Technology (Beverly, MA). Goat anti-rabbit horseradish peroxidase (HRP) conjugate was purchased from Bio-Rad Laboratories (Hercules, CA), goat anti-mouse HRP conjugate was purchased from BD Transduction Laboratories (Lexington, KY). Penicillin, streptomycin, RPMI1640 medium, fetal bovine serum (FBS), and $0.4 \%$ trypan blue vital stain were obtained from Invitrogen Corporation/ Life Technologies, Inc. (Grand Island, NY). Oligonucleotides were synthesized by The Midland Certified Reagent Company, Inc. (Midland, TX), dissolved in Polyethylenimine (PEI) (Aldrich Chemical, WI) as a $1 \mu \mathrm{g} / \mu 1$ stock solution, and stored at room temperature (RT).

Cell lines and cell culture. The cell lines used in our studies included: A549 (human non-small cell lung carcinoma); H292 (human lung epithelial cell carcinoma); and H359, H596, H1792, and H1299 cells, which were purchased from ATCC (Manassas, VA). These cell lines were cultured in DMEM medium supplemented with $10 \%$ FBS, 100 units/ml penicillin, and $100 \mu \mathrm{g} / \mathrm{ml}$ streptomycin.

Western blot analysis. To determine the effect of GQ-ODN on Stat 3 phosphorylation, cytoplasmic extracts were prepared, as previously described (14), from murine tumor tissue or A549 lung cancer cells that had been pretreated with GQ-ODN.
Lung tumor cells ( 1 million cells per well in 6-well plates) were first pre-treated with IL-6 $(25 \mathrm{ng} / \mathrm{ml})$ or EGF $(25 \mathrm{ng} / \mathrm{ml})$ for $30 \mathrm{~min}$. Cells were then washed in serum-free medium and incubated with various concentrations (1.4-142 $\mu \mathrm{M})$ of GQ-ODN/PEI complexes for $24 \mathrm{~h}$. Cells were lysed with cell lysis buffer and $30 \mu \mathrm{g}$ of whole cell protein was resolved on $10 \%$ SDS-PAGE gel, transferred to a nitrocellulose membrane, blocked with $5 \%$ nonfat milk, and probed with specific antibody against Stat3 and tyrosine-phosphorylated Stat3 (p-Stat3). Xenografted tumors were harvested at the end of treatment, diced into small pieces, and sonicated on ice for $2 \mathrm{~min}$. Tumor tissue $(100 \mathrm{mg}$ ) was lysed in $300 \mu \mathrm{l}$ of lysis buffer containing protease and phosphatase inhibitors. Tumor tissue protein $(50 \mu \mathrm{g})$ was resolved on SDS-PAGE and probed by specific antibodies, as previously described. The bands were quantitated using a Personal Densitometer Scanner (version 1.30) and ImageQuant software (version 3.3) (GE Healthcare/Amersham Biosciences).

Animal/xenograft model. Athymic nude mice (Balb-nu/nu, 4 weeks old, weighing approximately $20 \mathrm{~g}$ ) were obtained from Charles River Laboratories, Inc. (Wilmington, MA); 2.5 million A549 NSCLC cells in $200 \mu 1$ of PBS were then injected subcutaneously into the right flank of each mouse. After the NSCLC tumors were established $\left(50-150 \mathrm{~mm}^{3}\right)$, the nude mice were randomly assigned to 5 groups of 5 (or 4): Group 1, was treated with PEI $(2.5 \mathrm{mg} / \mathrm{kg})$ (vehicle) alone; Group 2 was treated with paclitaxel (a conventional chemotherapeutic agent) at $10 \mathrm{mg} / \mathrm{kg}$; Group 3 was treated with GQ-ODN T40214/PEI (10 mg/kg/+2.5 mg/kg); and Group 4 was treated with GQ-ODN T40231/PEI $(10 \mathrm{mg} / \mathrm{kg} /+2.5 \mathrm{mg} /$ $\mathrm{kg})$ and Group 5 was treated with ns-ODN/PEI $(10 \mathrm{mg} / \mathrm{kg} /$ $+2.5 \mathrm{mg} / \mathrm{kg}$ ) (control ODN). PEI and ODNs were administered every other day and paclitaxel was injected intraperitoneally (IP) every 4 days. Weight and tumor size were measured every other day. Tumor size was calculated by using the function [a $\left.\mathrm{x}\left(0.5^{\mathrm{b}}\right) 2\right]$, where a equals the length and $\mathrm{b}$ equals the width of tumors.

RNase protection assay (RPA). RPA was performed, as previously described $(19,20)$. Briefly, for each sample prepared from NSCLC tumor tissue, five micrograms of total RNA were used in the RNase protection assay. Probes specific to survivin, c-myc, and Mcl-1 mouse genes were prepared. Mouse Angio-1, Apo-2, and CYC-1 multi-probes were obtained from BD Biosciences/Pharmingen (San Diego, CA). An RNase protection assay was performed using a kit (Torrey Pines Biolabs, Inc.; Houston, TX), in accordance with the manufacturer's instructions. The ${ }^{32} \mathrm{P}[\mathrm{UTP}](3000 \mathrm{Ci} / \mathrm{mmol}, \mathrm{ICN})-$ labeled antisense RNA probes were synthesized using mCK5 multi-probes (BD Biosciences/Pharmingen) as templates, through an in vitro transcription system (Promega Corporation; Madison, WI). Antisense RNA probes were hybridized with the RNA samples at $90^{\circ} \mathrm{C}$ for $25 \mathrm{~min}$. Unhybridized singlestranded RNA was digested by ribonuclease A/T1 (SigmaAldrich; St. Louis, MO) for $30 \mathrm{~min}$. Double-stranded RNA was precipitated by stop solution at $-80^{\circ} \mathrm{C}$ for $15-30 \mathrm{~min}$, and centrifuged at maximum speed for $30 \mathrm{~min}$. The samples were resolved by $6 \%$ sequencing gel. Subsequently, the gels were dried and exposed to X-ray film. 
A. Control ODN: TGCCGGATCAAGAGCTACCA G-quartet ODNs: T40214: GGGCGGGCGGGCGGGC

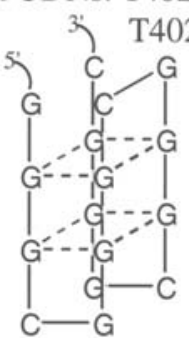

T40214

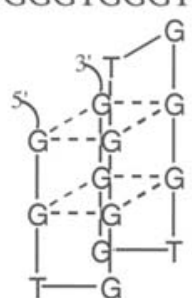

T40231
T40214

B.

C.

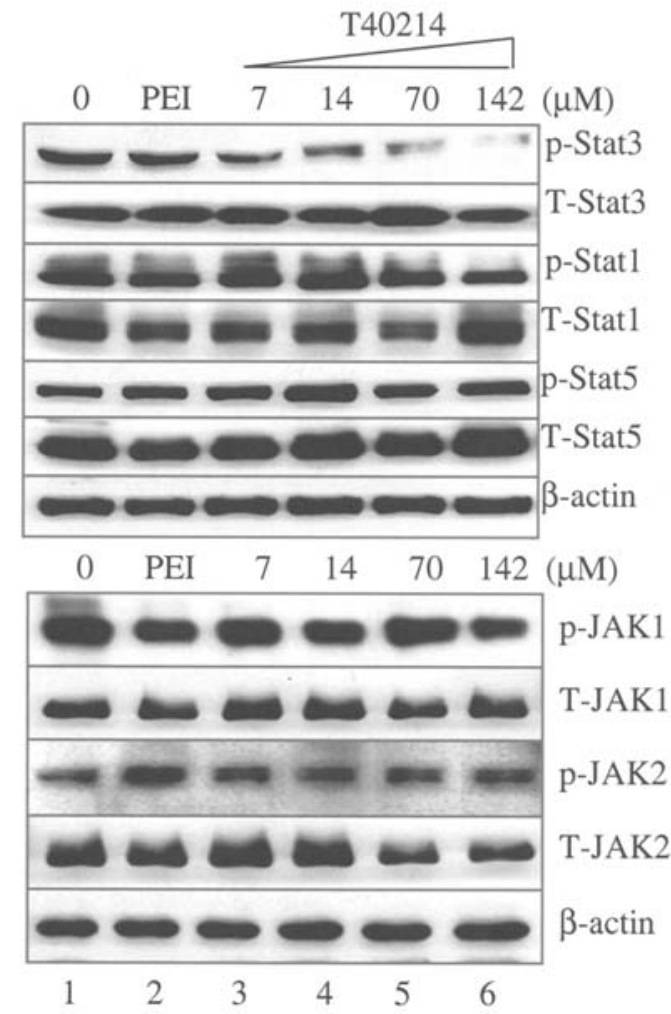

Figure 1. (A) The structures of GQ-ODN T40214 and T40231. (B) Western blot analysis shows the inhibition of Stat 3 phosphorylation by GQ-ODNs T40214 and T40231 in NSCLC cells (A549). Comparing with the control band (lane 1), T40214 significantly inhibited the expression of p-Stat3 in NSCLC cells (A549) $\left(\mathrm{IC}_{50}=5.4 \mu \mathrm{M}\right)$. p-Stat3 and T-Stat3, phosphorylated Stat3 and total Stat3, respectively. PEI did not inhibit p-Stat3 (lane 2), and GQ-ODN T40214 did not inhibit p-Stat1 and p-Stat5 in A549 cells. (C) T40214 did not inhibit the expression of p-JAK1 and p-JAK2 in A549 cells. $\beta$ actin served as the internal control.

Hematoxylin and eosin staining. Xenografted tumors were harvested from athymic mice treated with vehicle alone (PEI), GQ-ODN T40214, GQ-ODN T40231, and paclitaxel, fixed (with $10 \%$ formaldehyde in paraffin), sectioned (5- $\mu \mathrm{m}$ tissue sections) and stained with hematoxylin and eosin ( $\mathrm{H} \& \mathrm{E})$.

Terminal deoxyribonucleotidyl transferase-mediated dUTP nick end labeling (TUNEL) analysis. Tissue sections $(5 \mu \mathrm{m})$ were mounted on siliconized glass slides, air dried, and heated at $45^{\circ} \mathrm{C}$ overnight. After deparaffinization and rehydration, the sections were digested with proteinase $\mathrm{K}(120 \mu \mathrm{g} / \mathrm{ml})$ for $20 \mathrm{~min}$ at room temperature. Following quenching of the endogenous peroxidase activity, the sections were washed in PBS, and subsequently incubated with equilibration buffer for $10 \mathrm{~min}$ at room temperature. Sections were boiled and $50 \mu \mathrm{l}$ of a mix containing terminal deoxynucleotidyl transferase, reaction buffer containing dATP, and digoxigenin-11-dUTP was then added. The sections were covered with a plastic coverslip, washed in stop/wash buffer for $10 \mathrm{~min}$ at room temperature, and subsequently washed in PBS. The sections were then incubated with anti-digoxigenin peroxidase for $30 \mathrm{~min}$ at room temperature and washed in PBS. Color development was accomplished through immersion of the slides in 3'3 diaminobenzidine $/ 0.1 \% \mathrm{H}_{2} \mathrm{O}_{2}$ for 3-7 min. Sections were counterstained with ethyl green, washed in butanol, cleared in xylol and mounted with permount.

\section{Results}

Inhibition of Stat 3 activation by GQ-ODN. Recently, we have developed GQ-ODNs as a new class of Stat 3 inhibitors. We have previously reported that the leading compounds, $\mathrm{T} 40214$ and T40231, selectively inhibit Stat 3 activity $\left(\mathrm{IC}_{50}=\right.$ $5 \mu \mathrm{M})$ in the cells of prostate, breast and head and neck cancers $(14,16)$. Here we employed Western blotting to ascertain if GQ-ODN inhibits Stat3 phosphorylation in NSCLC cells. The sequences and structures of GQODN T40214 and T40231 have been previously delineated (Fig. 1A) (14). PEI (polyethylenimine) was used as vehicle for intracellular delivery of ODN at the ODN/PEI ratio of 4:1. $\beta$-actin was used as the loading control. When compared to the tyrosine-phosphorylated Stat3 (p-Stat3) band in lane 1, lane 2 shows that PEI alone has no inhibitory effect on p-Stat 3 in NSCLC cells. The p-Stat3 was significantly reduced when the concentration of T40214 increased (lanes 3 to 6 ). The $\mathrm{IC}_{50}$ of p-Stat 3 dephosphorylation for T40214 was $\sim 5.4 \mu \mathrm{M}$. Along with p-Stat3, we also detected tyrosine-phosphorylated Stat1 (p-Stat1) and Stat5 (p-Stat5) in NSCLC cells under similar experimental conditions. Importantly, we found that GQ-ODN T40214 does not inhibit the activation of p-Stat1 nor p-Stat5 in NSCLC cells, showing that GQ-ODN T40214 selectively inhibits p-Stat3 activation (Fig. 1B). Furthermore, tyrosine-phosphorylated JAK1 (pJAK1) and JAK2 (p-JAK2) were also detected in NSCLC cells; and were not found to be inhibited by GQ-ODN T40214. This further reinforces the specificity of GQ-ODN to the selective inhibition of Stat3 protein (Fig. 1C).

GQ-ODN suppressed the growth of NSCLC tumors. Assessing the effectiveness of a drug in animal models is an important step toward establishing its potential clinical utility. To this end, we utilized nude mice xenografts as animal models of in vivo drug testing in order to evaluate the anti-cancer potential of GQ-ODN. First, nude mice were injected subcutaneously with NSCLC cells (e.g., A549) in which Stat3 is constitutively active. After tumors were established (vol. 50 150 $\mathrm{mm}^{3}$ ), treatment of nude mice with NSCLC (A549) tumors was performed by intraperitoneal (IP) injection. The nude mice were randomly assigned to 5 groups (4 or 5 mice in each group): Group 1 was treated with PEI alone $(2.5 \mathrm{mg} / \mathrm{kg})$; Group 2 was treated with paclitaxel (a clinical drug) (10 mg/ $\mathrm{kg}$ ); Groups 3 and 4 were treated with T40231/PEI and T40214/PEI (10 mg/kg/+2.5 mg/kg), respectively; and Group 5 was treated by ns-ODN/PEI $(10 \mathrm{mg} / \mathrm{kg} /+2.5 \mathrm{mg} / \mathrm{kg})$. PEI and ODNs were administered every two days; paclitaxel was 


\section{A. Beginning of placebo-treatment Beginning of T40214-treatment}
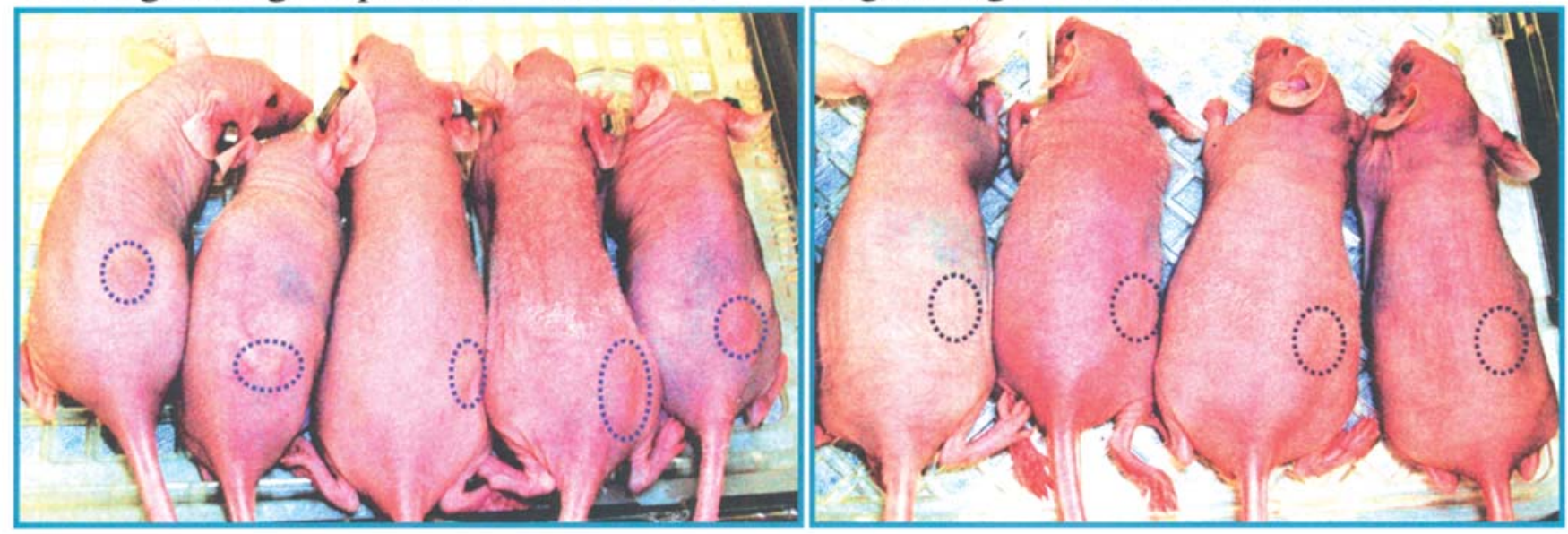

\section{B. After placebo-treatment}

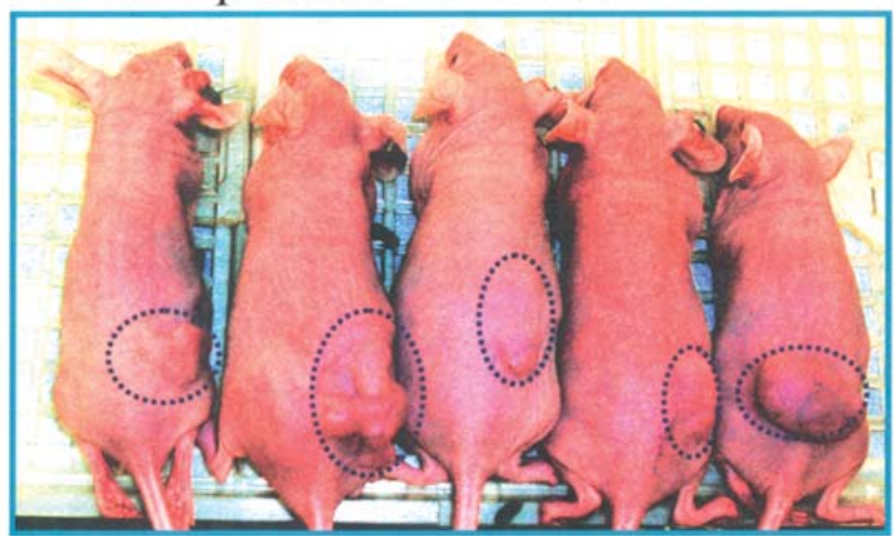

C.

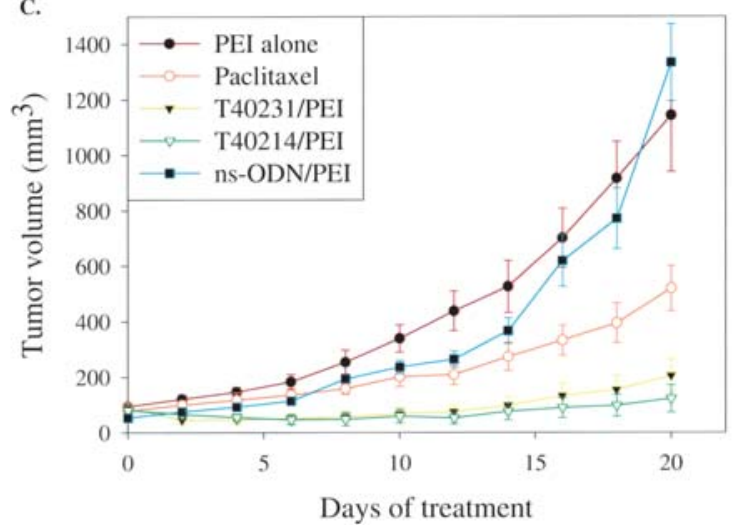

injected every four days, to ensure safety of the mice from toxicity. Results demonstrate that, over the 21-day treatment period, i) the mean size of NSCLC tumors in the PEI- and nsODN-treated mice increased from 93 to $1144 \mathrm{~mm}^{3}$ and from 53 to $1334 \mathrm{~mm}^{3}$, respectively; ii) the mean size of NSCLC tumors in the paclitaxel-treated mice increased from 88 to $519 \mathrm{~mm}^{3}$; and iii) the mean size of NSCLC tumors in the mice treated with T40231 and T40214 only increased from 89 to $204 \mathrm{~mm}^{3}$ and from 83 to $123 \mathrm{~mm}^{3}$, respectively (Fig. 2). Significant differences in tumor growth were observed between PEI-treated mice and T40214-treated $(\mathrm{p}=0.002)$ or T40231treated mice $(\mathrm{p}=0.004)$ and between the mice treated by ns-ODN (a control ODN) and by T40214 ( $\mathrm{p}=0.019)$ or by T40231 ( $\mathrm{p}=0.028)$ as well.
After T40214-treatment

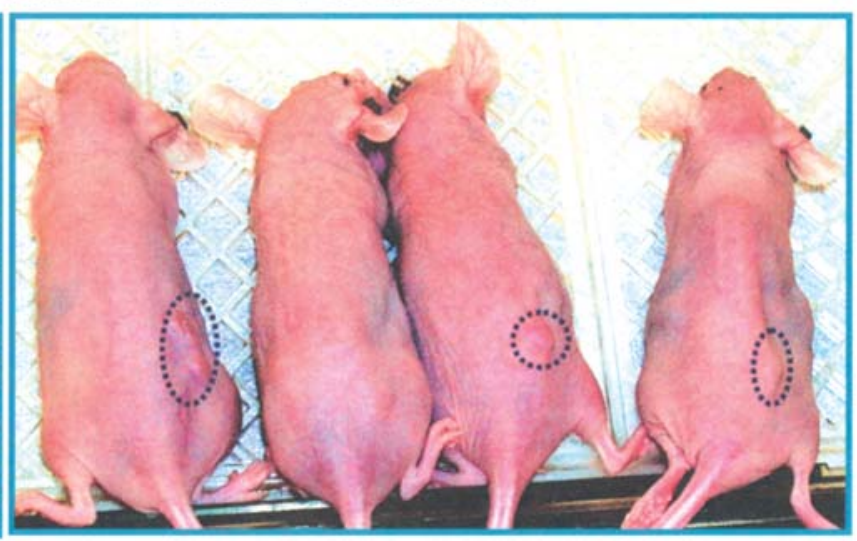

Figure 2. The photographs show nude mice with NSCLC tumors treated by PEI alone (left panels) and by GQ-ODN T40214/PEI (right panels) over a period of 21 days, (A) at the beginning of treatment and (B) at the end of treatment. (C) Tumor volumes versus days of drug treatment for the five groups of mice: i) treated by PEI alone; ii) treated by paclitaxel; iii) treated by T40231/PEI; iv) treated by T40214/PEI; and v) treated by ns-ODN/PEI.

Targets of GQODN. To determine the targets of GQ-ODN and possible mechanism of GQ-ODN suppressing tumor growth, we performed immunoblotting assays on tumor tissue, as described in Materials and methods. Results demonstrate the expression of p-Stat3 and its regulated proteins in NSCLC tumors (Fig. 3A). An equal amount of protein from each tumor sample was loaded, and the intensities of the bands from mice treated with T40214/PEI (lane 2), T40231/PEI (lane 3) or paclitaxel (lane 4), were compared with that from the PEItreated mice (lane 1). We found that GQ-ODN T40214 and T40231 totally blocked expression of phosphorylated Stat3 (p-Stat3) and its downstream proteins (i.e., $\mathrm{Bcl}-2, \mathrm{Bcl}-\mathrm{x}_{\mathrm{L}}$, Mcl-1, survivin, VEGF, Cyclin D1, and c-myc) in NSCLC tumors. However, paclitaxel did not inhibit p-Stat3, and only 
A.

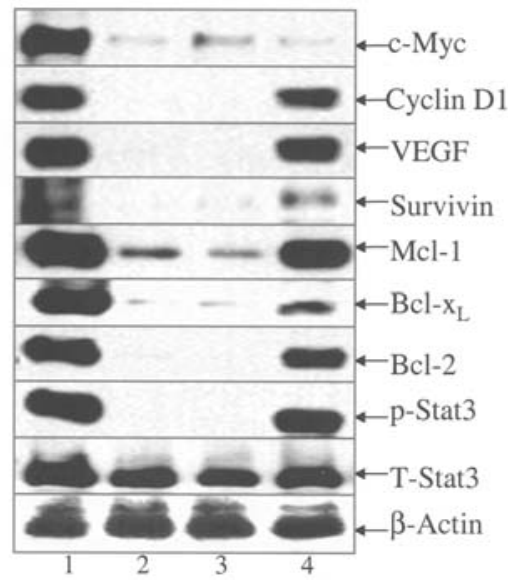

B.

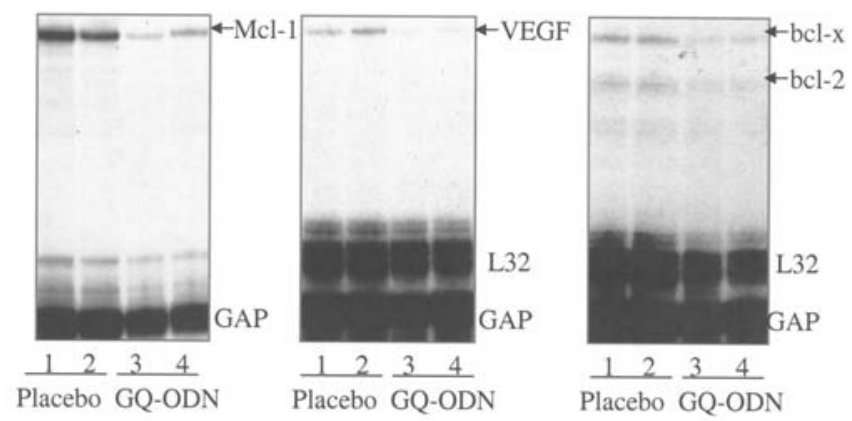

C.

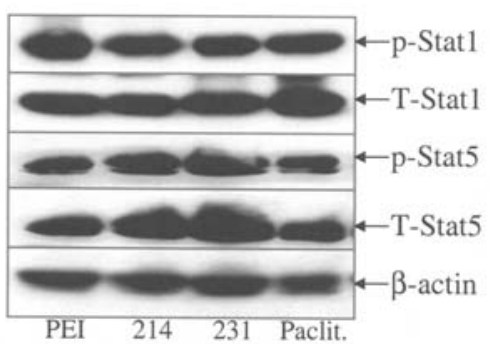

Figure 3. (A) Western blots obtained from NSCLC tumors demonstrate the expression of total Stat3 (T-Stat3), phosphorylated Stat3 (p-Stat3), and its downregulated proteins, including Bcl-2, Bcl- $\mathrm{x}_{\mathrm{L}}, \mathrm{Mcl}-1$, survivin, VEFG, Cyclin D1 and c-myc. Lane 1, tumor treated by PEI alone; lane 2, tumor treated by T40214/PEI; lane 3, tumor treated by T40231/PEI; and lane 4, tumor treated by paclitaxel. $\beta$ actin serves as the internal control. (B) RPA results were obtained from tumors of two PEI-treated mice (lanes 1 and 2) and two T40214-treated mice (lanes 3 and 4). The mRNA levels of the Stat3-regulated genes in T40214-treated tumors were much less than in the PEI-treated control tumors, showing that Stat3-regulated transcription of candidate genes, i.e. Mcl-1 (left), VEGF (middle), survivin (middle), Bcl- $\mathrm{x}_{\mathrm{L}}$, and Bcl-2 (right), was inhibited by GQ-ODNs. L32 and GAPDH represent internal controls. (C) GQ-ODN T40214 did not inhibit p-Stat1 and p-Stat5 activation in vivo. (C) The proteins of Stat 1 and Stat5 were obtained from the same tumor samples and under the same experimental conditions as Stat3. Comparing with proteins of total Stat1 (T-Stat1) and Stat5 (T-Stat5), T40214 and T40231 did not inhibit p-Stat1 and p-Stat5 in NSCLC tumors.

partially blocked expression of $\mathrm{Bcl}-\mathrm{x}_{\mathrm{L}}, \mathrm{Bcl}-2$, survivin, and c-myc in NSCLC tumors.

To determine whether the Stat3-regulated proteins (e.g., Bcl-2, Bcl- $\mathrm{x}_{\mathrm{L}}, \mathrm{Mcl}-1$, VEGF, and others) are inhibited by blocking Stat3 DNA transcription or directly by GQ-ODN, an RNase protection assay (RPA) was employed to test the
A. Placebo-treated tumor GQ-ODN-treated tumor

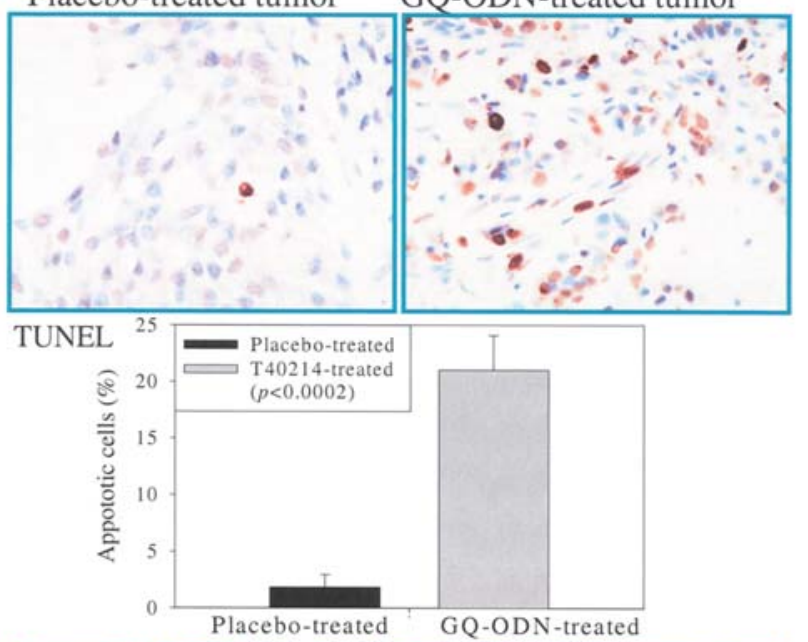

B.

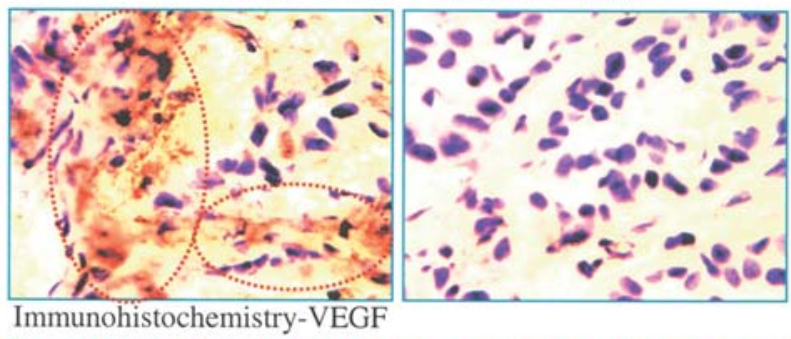

C.

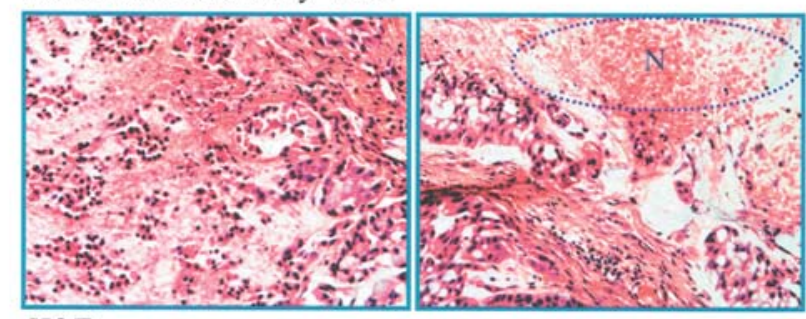

$H \& E$

Figure 4. (A) Apoptosis of cells induced by GQ-ODN T40214 in NSCLC tumors. TUNEL-stained slides demonstrate an absence of TUNEL-positive cells (i.e., no cells are stained dark brown) in placebo-treated tumors (top left panel), whereas GQ-ODN-treated tumors (top right panel) exhibited a high number of TUNEL-positive tumor cells (photographs x400 magnification). The ratio of apoptotic cells to total cells increased 10-fold from placebo-treated tumor (1.9\%) to T40214-treated tumor (21\%). (B) Immunohistochemistry data show that VEGF, which appears brown in the images, was highly expressed in the tissue of NSCLC tumors treated by PEI (the cycled areas); however, tumors treated by GQ-ODN T40214 showed no evidence of VEGF (photographs $\times 400$ magnification). (C) H\&E images show that in PEI-treated tumors (left), all NSCLC cells were intact. In contrast, in GQ-ODN-treated tumors (right) most NSCLC cells shrunk, partially resulting in necrosis (the circled area) (photographs x100 magnification).

mRNA of the Stat3-regulated genes in NSCLC tumors. The results, obtained from the tumors of two PEI-treated mice (lanes 1 and 2) and two T40214/PEI-treated mice (lanes 3 and 4), clearly show that the level of mRNA of Mcl-1, VEGF, bcl-x, and bcl-2 in T40214/PEI-treated tumors were much lower than those in the PEI-treated tumors (Fig. 3B). The mRNAs of L32 and GAP were equally loaded as controls. The RPA data provide solid evidence that GQ-ODNs inhibit the activation of Bcl-2, Bcl- $\mathrm{x}_{\mathrm{L}}$, Mcl-1, survivin, VEGF, Cyclin D1, and c-myc in NSCLC tumors through the disruption of Stat 3 transcription.

Independent of Stat3, Stat1 and Stat5 are also active in human cancers, including NSCLC; and therefore the selective 
A. Complex of p-Stat3 dimer/DNA

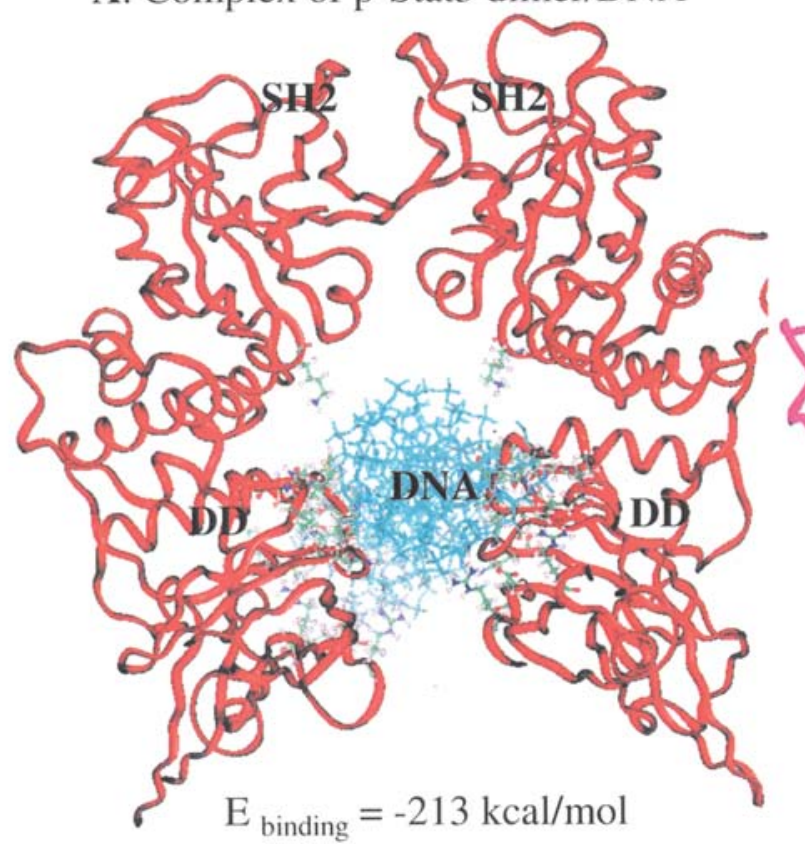

B. Complex of p-Stat3 dimer/T40214

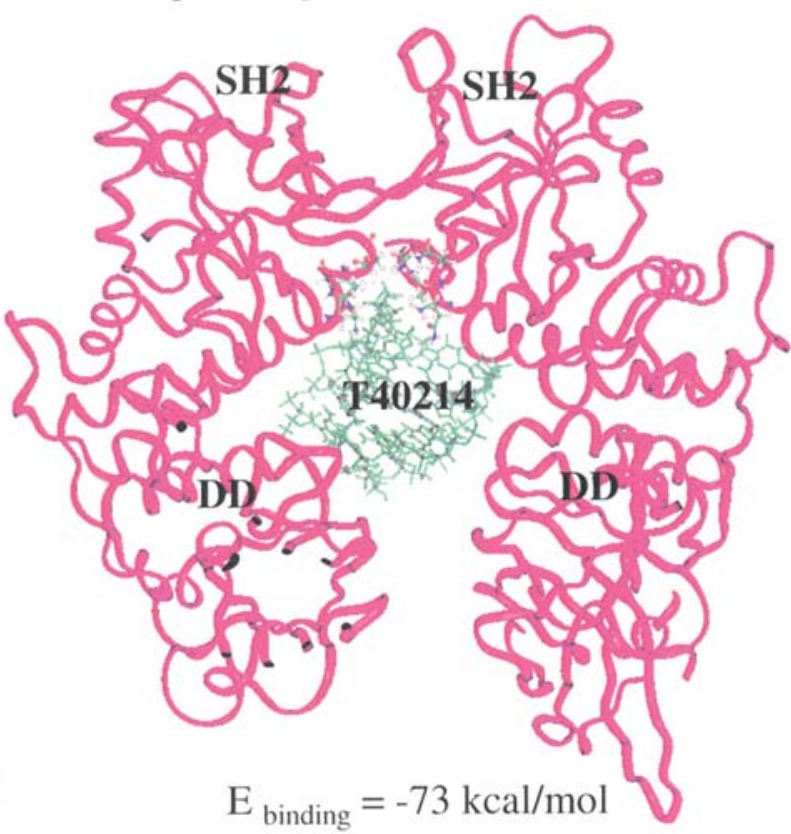

Figure 5. The complexes of p-Stat3 dimer with DNA and of p-Stat3 dimer with T40214 are demonstrated in A and B, respectively. The binding energies between Stat 3 dimer and DNA and between Stat 3 dimer and T40214 were calculated as $-231 \mathrm{kal} / \mathrm{mol}$ and $-73 \mathrm{kal} / \mathrm{mol}$, respectively. (A) $30 \mathrm{H}-\mathrm{bonds}$ are formed between p-Stat3 dimer and DNA in the residues of M331 to V432 of DNA binding domains (7), and (B) seven H-bonds are formed between p-Stat3 dimer and T40214 in the residues of Q643 to N647 of SH2 domains. The residues in Stat3 forming H-bonds with DNA or T40214 are shown in stick and ball types. DD denotes DNA binding domain and SH2 denotes $\mathrm{SH} 2$ domain.

targeting of Stat3 becomes a key factor in the development of a potent Stat 3 inhibitor. Using Western blot analysis we have shown that GQ-ODN T40214 and T40231 do not target Stat1 and Stat5. A comparison of the bands was made between T-Stat1 (total Stat1) and p-Stat1 and between T-Stat5 (total Stat5) and p-Stat5 of each tumor treated with PEI, T40214, T40231 and paclitaxel, respectively. Results demonstrate an absence of inhibition of Stat 1 and Stat5 activation in GQ-ODN T40214- and T40231-treated NSCLC tumors (Fig. 3C). These results from tumor tissues are consistent with that obtained from NSCLC cells.

Tumor apoptosis and angiogenesis. We set out to determine if suppression of tumor-growth by GQ-ODN T40214 and T40231 was associated with an increase in apoptosis and reduction in angiogenesis in tumors. The TUNEL assay based on labeling the apoptotic cells with cleaved DNA fragments at the single cell level was performed to quantify apoptosis in tumors and light microscopy was used for data analysis. The apoptotic tumor cells were stained dark brown via TUNEL-positive staining, and the normal tumor cells remained unstained. Results show significant apoptosis in NSCLC tumors treated by GQ-ODN T40214 (Fig. 4A, right panel), when compared with NSCLC tumors treated by PEI alone (Fig. 4A, left panel). The analyses of the TUNELpositive cells among total cells indicated that the percentage of apoptotic cells in PEI-treated tumors was $1.9 \%$ while that in T40214-treated tumors increased to $21.1 \%(\mathrm{p}<0.0002$, Wilcoxin rank sum test) (Fig. 4A, bottom panel).

VEGF staining was performed using immunohistochemistry with peroxidase-labeled secondary antibodies; negative controls (first incubation step, without primary antibody) were also included. When no staining was observed, the result was considered negative, whereas, moderate staining in the majority of the cells was considered positive. Slides were incubated with a mouse anti-VEGF monoclonal antibody. VEGF was highly expressed in the tissue of NSCLC tumors treated by PEI alone (the cycled areas) (Fig. 4B, left panel); however, VEGF was not observed in the tumors treated by GQ-ODN (Fig. 4B, right panel). These observations are consistent with the Western blotting results, which indicate that the expression of VEGF was totally blocked in GQ-ODN-treated tumors, but not in PEI-treated tumors. Microscopy with H\&E staining clearly showed GQ-ODN-treatment to cause tumor cell shrinkage with chromatin condensation and partial necrosis (Fig. 4C, right panel); in contrast, PEI-treatment did not result in such changes in tumors (Fig. 4C, left panel).

\section{Discussion}

Although chemotherapy provides a clinically significant benefit for patients with advanced NSCLC, the improvement of survival for these patients is only modest (21); thus, there is a need to search for novel therapeutics. Haura et al showed that p-Stat 3 was highly expressed in 54\% of NSCLC primary tumors, suggesting that Stat 3 is a promising molecular target for lung cancer (22). Our results show that when GQ-ODN was incubated with NSCLC cells for $24 \mathrm{~h}$, T40214 selectively inhibited Stat3 phosphorylation. Moreover, GQ-ODN T40214 did not inhibit the activation of JAK kinases, the upstream proteins of STAT. In addition, our results in cell and tumor clearly show that GQ-ODN selectively inhibits the activation of Stat3, but not Stat1 and Stat5, both in vitro and in vivo. The selective inhibition of Stat 3 activation for GQ-ODN in vivo 
is considered beneficial to prospective clinical studies with regard to GQ-ODN since this selective targeting of Stat3 becomes a key factor in the development of a potent Stat3 inhibitor. Independent of Stat3, Stat1 and Stat5 are also active in many human cancers (5). Stat5-induced cell survival promotion has a potent oncogenic role similar to Stat3 (21). Stat1, which acts in a pro-apoptotic and anti-proliferative manner, seems to be a tumor suppressor whose functions totally differ from those of Stat3 $(22,23)$.

In our previous studies $(14,16)$, we demonstrated that GQ-ODN predominantly interacts with the p-Stat3 dimer in the range of amino acid residues 638 to 652, within the SH2 domains. The selective inhibition of p-Stat 3 activity by GQODN is based upon a few critical residues that form a local structure different from that of p-Stat 1 dimer. In the p-Stat 3 dimer, the paired residues of Q643 and N646 repel one another to form a channel conformation, in which GQ-ODN is held by seven H-bonds. However, the corresponding paired-residues of Stat1 dimer, K637 and S640, lock the dimer together; thereby, blocking the interaction of GQ-ODN with Stat1. Destabilizing the complex between $\mathrm{p}$-Stat3 dimer and DNA is a critical step for the dephosphorylation of p-Stat3 by GQODN. GQ-ODN T40214 promotes p-Stat3 dephosphorylation by blocking DNA binding to p-Stat3 dimer and forming an unstable complex between GQ-ODN T40214 and p-Stat3 dimer (3D model shown in Fig. 5). This unstable complex will dephosphorylate faster than the DNA complex. Computational energy calculation supported this hypothesis. The binding energy for the complexes DNA/p-Stat3 dimer and GQ-ODN $\mathrm{T} 40214 / \mathrm{p}$-Stat 3 dimer are $-213 \mathrm{kcal} / \mathrm{mol}$ and $-73 \mathrm{kcal} / \mathrm{mol}$, respectively. This selective inhibition of Stat 3 phosphorylation observed in GQ-ODN-treated tumors (Fig. 3) is one of the greatest advantages of GQ-ODN as an anti-cancer drug.

We have demonstrated that T40214 and its analog T40231 totally blocked p-Stat 3 and its downstream target proteins, including anti-apoptotic proteins: $\mathrm{Bcl}-2, \mathrm{Bcl}-\mathrm{x}_{\mathrm{L}}, \mathrm{Mcl}-1$, and survivin; inducer of angiogenesis, VEGF; and the proteins for cell proliferation: Cyclin D1, and c-myc in tumor tissue (Fig. 3A). Additionally, we also have demonstrated that GQODN also blocks the transcription of Stat3-regulated genes: $\mathrm{Bcl}-2, \mathrm{Bcl}-\mathrm{X}_{\mathrm{L}}, \mathrm{Mcl}-1$, survivin, and VEGF in tumor tissue (Fig. 3B). To our knowledge, this is the first report to provide in vivo evidence of the relationship between Stat 3 and its regulated genes and proteins, although it has been observed in cell culture previously (5). The inhibition of Stat 3 protein induced a tremendous increase in apoptosis (Fig. 4A) and a concomitant decrease in angiogenesis (Fig. 4B) and cell proliferation in tumors, all of which strongly deter tumor growth. Consequently, the inhibition of Stat3 activation, which significantly promotes apoptosis and reduces angiogenesis and cell proliferation, strongly suppressed tumor growth.

Molecules of JAK/STAT signaling pathways, in particular Stat3, have been validated to be potential targets for cancer therapy and much effort has been made to develop novel anticancer drugs targeting Stat3 (24-49). Our systematic in vivo analysis $(14,16)$ has shown that GQ-ODN as an anti-cancer agent selectively targeted Stat 3 and significantly suppressed the tumor growth of a variety of tumors in nude mouse xenografts: prostate cancer $(\mathrm{p}=0.001)$; breast cancer $(\mathrm{p}=0.001)$; head and neck squamous cell carcinoma (HNSCC) $(\mathrm{p}<0.001)$; and NSCLC $(\mathrm{p}=0.002)$. This demonstrates that GQ-ODN has the capacity to be a potent Stat 3 inhibitor, and represents a novel and promising class of anti-cancer drug in the treatment of metastatic human tumors.

\section{Acknowledgments}

The authors wish to thank Maryann Mastrangelo for assisting in immuno-histochemistry and Judy Young for assisting in the revision of the manuscript. This study was in part supported by R01 CA104035, SPORE CA97007, SPORE CA58204 (to NJ) and DOD W81XWH-04-1-0142 (to LM).

\section{References}

1. Stewart BW and Kleihues P: Lung Cancer. World Cancer Report. IARC Press, Lyon, France, 2003.

2. Greenlee RT, Murray T, Bolden S and Wingo PA: Cancer statistics, 2000. CA Cancer J Clin 50: 7-33, 2000.

3. Cohen V and Khuri FR: Chemoprevention of lung cancer: current status and future prospects. Cancer Metastasis Rev 21: 349-362, 2002.

4. Ginsberg RJ, Goldberg M and Waters PF: Surgery in nonsmall cell lung cancer. In: Thoracic Oncology. Roth JA RJ, Weisenburger TH (eds). 2nd edition. W.B. Saunders Company, Philadelphia, PA, pp124-126, 1995.

5. Yu H and Jove R: The STATs of cancer - new molecular targets come of age. Nat Rev Cancer 4: 97-105, 2004.

6. Darnell JE Jr: STATs and gene regulation. Science 277: 1630-1635, 1997.

7. Becker S, Groner B and Muller CW: Three-dimensional structure of the Stat3beta homodimer bound to DNA. Nature 394: 145-151, 1998.

8. Chen X, Vinkemeier U, Zhao Y, Jeruzalmi D, Darnell JE Jr and Kuriyan J: Crystal structure of a tyrosine phosphorylated STAT-1 dimer bound to DNA. Cell 93: 827-839, 1998.

9. Buettner R, Mora LB and Jove R: Activated STAT signaling in human tumors provides novel molecular targets for therapeutic intervention. Clin Cancer Res 8: 945-954, 2002.

10. Mora LB, Buettner R, Seigne J, Diaz J, Ahmad N, Garcia R, Bowman T, Falcone R, Fairclough R, Cantor A, Muro-Cacho C, Livingston S, Karras J, Pow-Sang J and Jove R: Constitutive activation of Stat 3 in human prostate tumors and cell lines: direct inhibition of Stat 3 signaling induces apoptosis of prostate cancer cells. Cancer Res 62: 6659-6666, 2002.

11. Dolled-Filhart M, Camp RL, Kowalski DP, Smith BL and Rimm DL: Tissue microarray analysis of signal transducers and activators of transcription 3 (Stat3) and phospho-Stat3 (Tyr705) in node-negative breast cancer shows nuclear localization is associated with a better prognosis. Clin Cancer Res 9: 594-600, 2003.

12. Nagpal JK, Mishra R and Das BR: Activation of Stat-3 as one of the early events in tobacco chewing-mediated oral carcinogenesis. Cancer 94: 2393-2400, 2002.

13. Song L, Turkson J, Karras JG, Jove R and Haura EB: Activation of Stat 3 by receptor tyrosine kinases and cytokines regulates survival in human non-small cell carcinoma cells. Oncogene 22: 4150-4165, 2003.

14. Jing N, Li Y, Xiong W, Sha W, Jing L and Tweardy DJ: G-quartet oligonucleotides: a new class of signal transducer and activator of transcription 3 inhibitors that suppresses growth of prostate and breast tumors through induction of apoptosis. Cancer Res 64: 6603-6609, 2004.

15. Jing N, Sha W, Li Y, Xiong W and Tweardy DJ: Rational drug design of G-quartet DNA as anti-cancer agents. Curr Pharm Des 11: 2841-2854, 2005.

16. Jing N, Zhu Q, Yuan P, Li Y, Mao L and Tweardy DJ: Targeting signal transducer and activator of transcription 3 with G-quartet oligonucleotides: a potential novel therapy for head and neck cancer. Mol Cancer Ther 5: 279-286, 2006.

17. Zhong M, Henriksen MA, Takeuchi K, Schaefer O, Liu B, ten Hoeve J, Ren Z, Mao X, Chen X, Shuai K and Darnell JE Jr: Implications of an antiparallel dimeric structure of nonphosphorylated STAT1 for the activation-inactivation cycle. Proc Natl Acad Sci USA 102: 3966-3971, 2005. 
18. Darnell JE: Validating Stat3 in cancer therapy. Nat Med 11: 595-596, 2005.

19. Feng L, Garcia GE, Yang Y, Xia Y, Gabbai FB, Peterson OW, Abraham JA, Blantz RC and Wilson CB: Heparin-binding EGFlike growth factor contributes to reduced glomerular filtration rate during glomerulonephritis in rats. J Clin Invest 105: 341-350, 2000.

20. Chen S, Bacon KB, Li L, Garcia GE, Xia Y, Lo D, Thompson DA, Siani MA, Yamamoto T, Harrison JK and Feng L: In vivo inhibition of $\mathrm{CC}$ and $\mathrm{CX} 3 \mathrm{C}$ chemokine-induced leukocyte infiltration and attenuation of glomerulonephritis in WistarKyoto (WKY) rats by vMIP-II. J Exp Med 188: 193-198, 1998.

21. Debierre-Grockiego F: Anti-apoptotic role of STAT5 in haematopoietic cells and in the pathogenesis of malignancies. Apoptosis 9: 717-728, 2004.

22. Reck M and Gatzemeier U: Chemotherapy in stage-IV NSCLC. Lung Cancer 45 (suppl 2): S217-S222, 2004

23. O'Shea JJ, Gadina M and Schreiber RD: Cytokine signaling in 2002: new surprises in the Jak/Stat pathway. Cell 109 (suppl): S121-S131, 2002.

24. Turkson J, Ryan D, Kim JS, Zhang Y, Chen Z, Haura E, Laudano A, Sebti S, Hamilton AD and Jove R: Phosphotyrosyl peptides block Stat3-mediated DNA binding activity, gene regulation, and cell transformation. J Biol Chem 276: 45443-45455, 2001.

25. Stahl N, Farruggella TJ, Boulton TG, Zhong Z, Darnell JE Jr and Yancopoulos GD: Choice of STATs and other substrates specified by modular tyrosine-based motifs in cytokine receptors. Science 267: 1349-1353, 1995.

26. Shao H, Cheng HY, Cook RG and Tweardy DJ: Identification and characterization of signal transducer and activator of transcription 3 recruitment sites within the epidermal growth factor receptor. Cancer Res 63: 3923-3930, 2003.

27. Wiederkehr-Adam M, Ernst P, Muller K, Bieck E, Gombert FO, Ottl J, Graff P, Grossmuller F and Heim MH: Characterization of phosphopeptide motifs specific for the Src homology 2 domains of signal transducer and activator of transcription 1 (STAT1) and STAT3. J Biol Chem 278: 16117-16128, 2003.

28. Coleman DR, Ren Z, Mandal PK, Cameron AG, Dyer GA, Muranjan S, Campbell M, Chen X and McMurray JS: Investigation of the binding determinants of phosphopeptides targeted to the SRC homology 2 domain of the signal transducer and activator of transcription 3. Development of a high-affinity peptide inhibitor. J Med Chem 48: 6661-6670, 2005.

29. Grandis JR, Drenning SD, Zeng Q, Watkins SC, Melhem MF, Endo S, Johnson DE, Huang L, He Y and Kim JD: Constitutive activation of Stat 3 signaling abrogates apoptosis in squamous cell carcinogenesis in vivo. Proc Natl Acad Sci USA 97: 4227-4232, 2000.

30. Niu G, Shain KH, Huang M, Ravi R, Bedi A, Dalton WS, Jove R and $\mathrm{Yu} \mathrm{H}$ : Overexpression of a dominant-negative signal transducer and activator of transcription 3 variant in tumor cells leads to production of soluble factors that induce apoptosis and cell cycle arrest. Cancer Res 61: 3276-3280, 2001.

31. Epling-Burnette PK, Liu JH, Catlett-Falcone R, Turkson J, Oshiro M, Kothapalli R, Li Y, Wang JM, Yang-Yen HF, Karras J, Jove R and Loughran TP Jr: Inhibition of STAT3 signaling leads to apoptosis of leukemic large granular lymphocytes and decreased Mcl-1 expression. J Clin Invest 107: 351-362, 2001.

32. Leong PL, Andrews GA, Johnson DE, Dyer KF, Xi S, Mai JC, Robbins PD, Gadiparthi S, Burke NA, Watkins SF and Grandis JR: Targeted inhibition of Stat3 with a decoy oligonucleotide abrogates head and neck cancer cell growth. Proc Natl Acad Sci USA 100: 4138-4143, 2003.

33. Meydan N, Grunberger T, Dadi H, Shahar M, Arpaia E, Lapidot Z, Leeder JS, Freedman M, Cohen A, Gazit A, Levitzki A and Roifman CM: Inhibition of acute lymphoblastic leukaemia by a Jak-2 inhibitor. Nature 379: 645-648, 1996.

34. Faderl S, Ferrajoli A, Harris D, Van Q, Priebe W and Estrov Z: WP-1034, a novel JAK-STAT inhibitor, with proapoptotic and antileukemic activity in acute myeloid leukemia (AML). Anticancer Res 25: 1841-1850, 2005.
35. Blaskovich MA, Sun J, Cantor A, Turkson J, Jove R and Sebti SM: Discovery of JSI-124 (cucurbitacin I), a selective Janus kinase/signal transducer and activator of transcription 3 signaling pathway inhibitor with potent antitumor activity against human and murine cancer cells in mice. Cancer Res 63: 1270-1279, 2003.

36. Rajasingh J, Raikwar HP, Muthian G and Johnson C: Curcumin induces growth-arrest and apoptosis in association with the inhibition of constitutively active JAK-STAT pathway in T cell leukemia. Biochem Biophys Res Commun 340: 359-368, 2006.

37. Shi X, Franko B, Frantz C, Amin HM and Lai R: JSI-124 (cucurbitacin I) inhibits Janus kinase-3/signal transducer and activator of transcription-3 signalling, downregulates nucleophosmin-anaplastic lymphoma kinase (ALK), and induces apoptosis in ALK-positive anaplastic large cell lymphoma cells. Br J Haematol 135: 26-32, 2006.

38. Song L, Morris M, Bagui T, Lee FY, Jove R and Haura EB: Dasatinib (BMS-354825) selectively induces apoptosis in lung cancer cells dependent on epidermal growth factor receptor signaling for survival. Cancer Res 66: 5542-5548, 2006.

39. Lee YK, Isham CR, Kaufman SH and Bible KC: Flavopiridol disrupts STAT3/DNA interactions, attenuates STAT3-directed transcription, and combines with the Jak kinase inhibitor AG490 to achieve cytotoxic synergy. Mol Cancer Ther 5: 138-148, 2006.

40. Chakravarti N, Myers JN and Aggarwal BB: Targeting constitutive and interleukin-6-inducible signal transducers and activators of transcription 3 pathway in head and neck squamous cell carcinoma cells by curcumin (diferuloylmethane). Int J Cancer 119: 1268-1275, 2006.

41. Cuevas P, Diaz-Gonzalez D, Sanchez I, Lozano RM, GimenezGallego $G$ and Dujovny M: Dobesilate inhibits the activation of signal transducer and activator of transcription 3 , and the expression of cyclin D1 and bcl-XL in glioma cells. Neurol Res 28: 127-130, 2006.

42. Kotha A, Sekharam M, Cilenti L, Siddiquee K, Khaled A, Zervos AS, Carter B, Turkson J and Jove R: Resveratrol inhibits Src and Stat 3 signaling and induces the apoptosis of malignant cells containing activated Stat 3 protein. Mol Cancer Ther 5: 621-629, 2006.

43. Amit-Vazina M, Shishodia S, Harris D, Van Q, Wang M, Weber D, Alexanian R, Talpaz M, Aggarwal BB and Estrov Z: Atiprimod blocks STAT3 phosphorylation and induces apoptosis in multiple myeloma cells. Br J Cancer 93: 70-80, 2005.

44. Nam S, Buettner R, Turkson J, Kim D, Cheng JQ, Muehlbeyer S, Hippe F, Vatter S, Merz KH, Eisenbrand G and Jove R: Indirubin derivatives inhibit Stat3 signaling and induce apoptosis in human cancer cells. Proc Natl Acad Sci USA 102: 5998-6003, 2005.

45. Venkatasubbarao K, Choudary A and Freeman JW: Farnesyl transferase inhibitor (R115777)-induced inhibition of STAT3(Tyr705) phosphorylation in human pancreatic cancer cell lines require extracellular signal-regulated kinases. Cancer Res 65: 2861-2871, 2005.

46. Sun J, Blaskovich MA, Jove R, Livingston SK, Coppola D and Sebti SM: Cucurbitacin Q: a selective STAT3 activation inhibitor with potent antitumor activity. Oncogene 24: 3236-3245, 2005.

47. Turkson J, Zhang S, Palmer J, Kay H, Stanko J, Mora LB, Sebti S, $\mathrm{Yu} \mathrm{H}$ and Jove R: Inhibition of constitutive signal transducer and activator of transcription 3 activation by novel platinum complexes with potent antitumor activity. Mol Cancer Ther 3: 1533-1542, 2004.

48. Barton BE, Murphy TF, Shu P, Huang HF, Meyenhofer M and Barton A: Novel single-stranded oligonucleotides that inhibit signal transducer and activator of transcription 3 induce apoptosis in vitro and in vivo in prostate cancer cell lines. Mol Cancer Ther 3: 1183-1191, 2004.

49. Bharti AC, Donato N and Aggarwal BB: Curcumin (diferuloylmethane) inhibits constitutive and IL-6-inducible STAT3 phosphorylation in human multiple myeloma cells. J Immunol 171: 3863-3871, 2003. 